\title{
Article \\ Simplified Pushover Analysis for Rapid Assessment of Shear-Type Frames
}

\author{
Raihan Rahmat Rabi ${ }^{1,2}, * \mathbb{D}$, Marco Vailati ${ }^{2}{ }^{(1)}$ and Giorgio Monti ${ }^{1,3}$ \\ 1 Department of Structural Engineering and Geotechnics, Sapienza University of Rome, Via A. Gramsci 53, \\ 00197 Roma, Italy; giorgio.monti@uniroma1.it \\ 2 Department of Civil, Construction-Architectural and Environmental Engineering, University of L'Aquila, \\ Piazzale Ernesto Pontieri, Monteluco, Poggio di Roio, 67100 L'Aquila, Italy; marco.vailati@univaq.it \\ 3 College of Engineering and Architecture, Zhejiang University, 866 Yuhangtang Road, \\ Hangzhou 310058, China \\ * Correspondence: raihan.rahmatrabi@uniroma1.it
}

Citation: Rahmat Rabi, R.

Vailati, M.; Monti, G. Simplified

Pushover Analysis for Rapid Assessment of Shear-Type Frames. Appl. Sci. 2021, 11, 11711. https:// doi.org/10.3390/app112411711

Academic Editors: Sara Cattaneo and Manuela Alessandra Scamardo

Received: 8 November 2021

Accepted: 7 December 2021

Published: 9 December 2021

Publisher's Note: MDPI stays neutral with regard to jurisdictional claims in published maps and institutional affiliations.

Copyright: (c) 2021 by the authors. Licensee MDPI, Basel, Switzerland. This article is an open access article distributed under the terms and conditions of the Creative Commons Attribution (CC BY) license (https:// creativecommons.org/licenses/by/ $4.0 /)$
Abstract: A simplified pushover method for rapidly assessing the seismic capacity of shear-type frames is presented. The frame global force-displacement capacity is described as a trilinear curve passing through three limit states (LS): Damage LS (DLS), Life safety LS (LLS), and Collapse LS (CLS). The global LSs are obtained consequently to the attainment of story-level, element-level, and section-level LSs. All LS capacities are described through closed-form equations. The validity of the proposed method is verified by applying it on several reinforced concrete (RC) frames with a varying number of stories. The results obtained with such an analytical procedure show a good match with those obtained from pushover based on finite element method (FEM) analysis models, in terms of both global force-displacement capacity curves and story displacements at various LSs. The proposed method has the potential to be conveniently applied in large-scale vulnerability/risk assessment studies, where the quality and quantity of the available data call for the use of simplified yet accurate models. More refined models would in fact require significantly heavier computational efforts, not justified by the quality of the results that are usually obtained. The simplicity of the proposed method in such a context is demonstrated through the development of the fragility curves of a five-story shear-type reinforced concrete frame, starting from a predefined set of mechanical and geometrical features characterizing a building typology.

Keywords: analytical pushover analysis; seismic assessment; shear-type frames; seismic vulnerability; fragility curves

\section{Introduction}

Seismic risk estimation and mitigation has become increasingly important due to the losses sustained by infrastructure, buildings, and humans in the aftermath of earthquakes around the world. Seismic risk is a composition of hazard, exposure, and vulnerability. The latter is where the efforts of the structural engineering community are focused, since it can be mitigated by retrofitting interventions applied on seismically deficient buildings. Two nonlinear procedures are available for the seismic assessment of structures: (a) nonlinear dynamic analysis (NDA) [1] and (b) nonlinear static analysis, also known as pushover analysis [2,3]. NDA, which allows estimating the structural nonlinear behavior and its evolution over time, is undoubtedly the most accurate and complete analysis procedure. However, some issues limit its application in the professional practice: (a) the selection of the analysis parameters is critical and can significantly influence the outcome; (b) numerous analysis with different accelerograms have to be carried out to obtain a statistically significant description of the structural seismic response; (c) the accuracy of the response depends on the adopted convergence criterion; (d) the interpretation of the analysis results is not straightforward, especially under a combined action in the two main directions; 
for example, in the Italian construction code [4]. Alternatively, pushover analysis aims to describe the dynamic nonlinear response of a structure through the application of an equivalent static system of forces or displacements. The method is relatively simple to use, and the results obtained are easy to interpret, since the response can be depicted in the form of a curve showing the variation of the total base-shear as a function of the displacement of a certain control point. The profile of the forces distribution along the height can be either fixed or adaptive. The fixed profile is effective in estimating the response of low-to-mid-height structures where the contribution of higher modes is negligible, and the plastic deformations are well distributed throughout the height [5-12]. The adaptive profile is applied in assessment of taller irregular structures where the deformation and inertial forces are not dominated by first mode [13-16].

Pushover analysis was originally formulated for single degree-of-freedom systems [17-19] but is now extensively used for the assessment of regular and irregular multistory buildings and bridge structures [20-22]. In the literature, there are currently different formulations suggested for pushover analysis, with a detailed indication of the pros and cons of each formulation presented in [23]. Pushover analysis is now recognized as a reliable assessment procedure, with the capability of guiding towards the identification of critical components in a structure [24]. It is therefore recommended as an effective assessment tool by a number of codes around the world $[4,23,25,26]$.

Despite the recognized advantages of the standard pushover analysis, its application in performing large-scale analyses (for example, territorial risk/vulnerability assessments) is limited because of its extensive computational load, due to the numerous calculation steps needed to follow the entire structural response well into the nonlinear range. For this reason, the development of a non-iterative simplified pushover procedure is essential to provide an acceptable compromise between accuracy and computational effort. An analytical simplified procedure for pushover analysis has already been proposed for the case of existing masonry structures [27] and of masonry building clusters [28,29].

The objective of this study is to adopt an approach similar to those earlier studies and to arrive at proposing a simplified non-iterative analytical model that can be used, both for the preliminary structural assessment of shear-type frames and for performing large-scale territorial studies.

\section{Displacement Capacity of a 2D Frame}

\subsection{Simplified Analytical Model of a 2D Frame}

The proposed analytical pushover method is thought to be applied to buildings that can be represented through a 2D frame, which is often the case when studying the response of large building stocks on a territory. A 2D frame is treated as a series system of stories, which are in turn parallel systems of columns, which are in turn series systems of different resisting mechanisms. A mechanical idealization of a two-story 2D frame is depicted in Figure 1, where each column is shown as a series system of flexural $(M)$ and shear capacity, of both column $(V)$ and end joint $\left(V_{j}\right)$. Despite the simplified representation, this (stick-)model provides a good compromise between accuracy and computational effort. It is especially applicable to buildings designed for gravity loads exhibiting a shear-type behavior, which implies that the damage is sustained by the columns only. The beams are assumed to remain elastic, representing the strong-beam/weak-column situation typically found in most existing buildings designed to obsolete codes. 


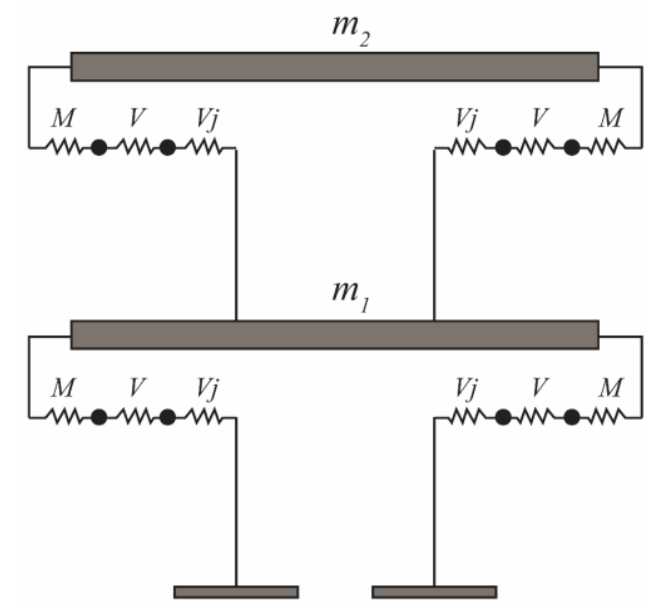

Figure 1. Mechanical idealization of an example two-story one-bay 2D frame with column-driven failure, where in each column three resisting mechanisms are considered: bending $(M)$, shear $(V)$, and joint shear $\left(V_{j}\right)$.

The global capacity of the 2D frame is obtained in terms of total base-shear and top-displacement. This is defined by a trilinear curve, where three objectively measured limit states (LSs) are identified: Damage Limit State (DLS), Life safety Limit State (LLS), and Collapse Limit State (CLS). These global LSs are determined at the attainment of the corresponding LSs at the story levels, which are in turn defined by the attainment of the corresponding LSs of the pertaining columns, which are in turn defined by the attainment of the corresponding LSs of the resisting mechanisms. This implies that global LSs are a direct consequence of local LSs attained at the sectional level. This criterion provides a consistent relationship between local and global LSs, thus avoiding resorting to different metrics for the latter, such as interstorey drifts.

The following sections show the sequential steps of the simplified pushover method, from the definition of the sectional capacity to that of the columns, to that of the stories, and, finally, to that of the entire frame.

\subsection{Moment-Curvature Relationship for the Three LSs}

The trilinear curve in Figure 2 describes the three limit states in a sectional momentcurvature diagram. The criteria adopted for defining the sectional LSs are: DLS (Damage Limit State), corresponds to tensile reinforcing bars yielding; LLS (Life safety Limit State), corresponds to concrete cover crushing; and CLS (Collapse prevention Limit State), corresponds to concrete core crushing. The coordinates of these points are given in terms of curvature $\phi_{x L S}$ and moment $M_{x L S}$ capacity, where $x=D, L, C$ for DLS, LLS, and CLS.

The corresponding equations for rectangular sections with symmetrical reinforcement, extended from [30], are shown in Table 1, with the notation in Figure 3, where $d$ is the section depth, $b$ is the section base, $d_{c}=b_{y}$ is the section depth at collapse, $A_{s}$ is the tension steel area, $A_{s w}$ is the stirrup area, and $s$ is the stirrup spacing. In addition, $\varepsilon_{y}$ is the steel yield strain, $\varepsilon_{\mathcal{C} u}$ is the ultimate concrete strain, and $f_{c}$ is the compressive concrete strength, while $\omega_{S}$ is the longitudinal reinforcement mechanical ratio and $n_{S}$ is the normalized axial load, given as:

$$
\omega_{s}=\frac{A_{s} f_{y}}{b d f_{c}} \quad \text { and } \quad n_{S}=\frac{N_{S}}{b d f_{c}}
$$




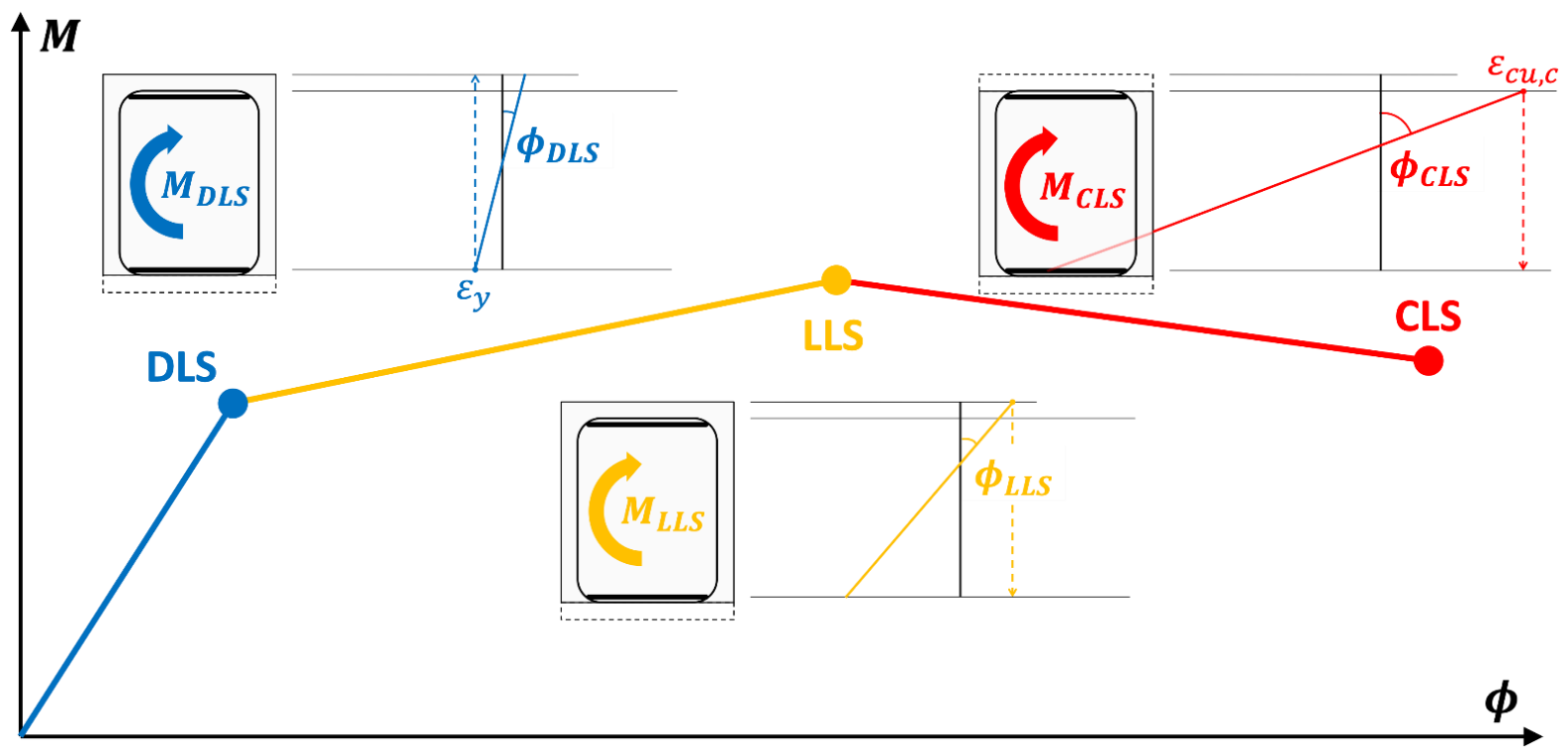

Figure 2. Moment-curvature relationship of a column section with the corresponding limit state criteria for Damage limitation Limit State (DLS, tension steel yielding), Life safety Limit State (LLS, concrete cover crushing), and Collapse prevention Limit State (CLS, concrete core crushing).

Table 1. Equations for moment and curvature capacity at three LSs for the case of rectangular sections with symmetric rebars.

\begin{tabular}{cc}
\hline & Damage Limitation Limit State (DLS) \\
\hline Moment capacity & $M_{D L S}=\frac{\varepsilon_{y}^{2}}{\varepsilon_{c u}^{2}}\left[0.45 n_{S}\left(0.8-n_{S}\right)+2.4\left(\omega_{S}+0.015\right)\right] b d^{2} f_{c}$ \\
\hline Curvature capacity & $\phi_{D L S}=\frac{\varepsilon_{y}}{2 d}\left(3+\sqrt{n_{S}}\right)$ \\
\hline Moment capacity & Life Safety Limit State (LLS) \\
\hline Curvature capacity & $M_{L L S}=\left[\omega_{S}+\frac{1}{2} n_{S}\left(1-\frac{n_{S}}{\eta_{f}}\right)\right] b d^{2} f_{c}$ \\
\hline & Collapse Prevention Limit State (CLS) \\
\hline Moment capacity & $\phi_{C L S}=\left[\omega_{S}+\frac{1}{2} n_{S}\left(1-\frac{\varepsilon_{c u}}{n_{S}}\right)\right] b d_{c}^{2} f_{c}$ \\
\hline Curvature capacity & $\phi_{C L S}=\phi_{L L S} \frac{d}{d_{c}}\left(1+\frac{1}{4} \frac{\widetilde{\sigma}_{2}}{\varepsilon_{c u}}\right)$ \\
\hline
\end{tabular}

Moreover, $\widetilde{\sigma}_{2}$ is the confining stress normalized with respect to the characteristic compressive concrete strength $f_{c k}$, which can be computed as follows:

$$
\widetilde{\sigma}_{2}=\alpha_{n} \cdot \alpha_{s} \cdot \frac{1}{3} \omega_{w}
$$

where:

$$
\begin{aligned}
& \alpha_{n}=\left(1-\frac{\sum b_{i}^{2}}{6 b_{x} b_{y}}\right) \approx 1-\frac{1}{3 b_{x} b_{y}}\left(\frac{b_{x}^{2}}{n_{c t, y}+1}+\frac{b_{y}^{2}}{n_{c t, x}+1}\right) \\
& \alpha_{s}=\left(1-\frac{s}{2 b_{x}}\right)\left(1-\frac{s}{2 b_{y}}\right) \\
& \omega_{w}=\frac{A_{s w, x} b_{x}+A_{s w, y} b_{y}}{b_{x} b_{y} s} \cdot \frac{f_{y}}{f_{c}}
\end{aligned}
$$

where $b_{i}$ is the distance between consecutive engaged bars, $b_{x}$ and $b_{y}$ are the sides of the confined concrete core in the two directions, $n_{c t, x}$ and $n_{c t, y}$ are the number of cross-ties in 
the two directions, and $A_{s w, x}$ and $A_{s w, y}$ are the stirrup areas in the two directions (Figure 3). Note that the approximation in Equation (3) applies if the rebars are evenly distributed along the section sides; otherwise, the more general relationship should be used.

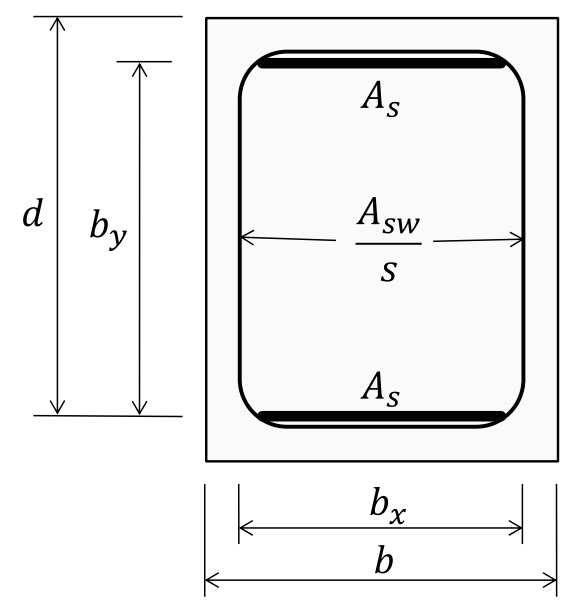

Figure 3. Cross-section with geometric parameters: $d$ is the section depth, $b$ is the section width, $b_{x}$ is the concrete core width, $b_{y}=d_{c}$ is the section depth at collapse, $A_{s}$ is the tension steel area (equal to that in compression), $A_{s w}$ is the stirrup area, and $s$ is the stirrup spacing.

Finally, $\eta_{f}$ is the compressive concrete strength increase due to confinement, given as:

$$
\eta_{f}= \begin{cases}1.000+5.0 \widetilde{\sigma}_{2} & \widetilde{\sigma}_{2} \leq 0.05 \\ 1.125+2.5 \widetilde{\sigma}_{2} & \widetilde{\sigma}_{2}>0.05\end{cases}
$$

When needed, the sectional curvature ductility at CLS can be calculated as:

$$
\mu_{\phi, C L S}=\frac{\phi_{C L S}}{\phi_{D L S}} \approx \frac{1}{2} \frac{\eta_{f}}{\varepsilon_{y} n_{S}}\left(\varepsilon_{c u}+\frac{1}{4} \widetilde{\sigma_{2}}\right)
$$

\subsection{Element Capacity for the Three LSs}

In those cases where a strong-beam/weak-column situation occurs, the global capacity depends only on the columns. A column is considered as a series system of flexural plastic hinges, column shear, and joints shear.

The force-displacement capacity of a column exhibiting a flexural behavior is determined by considering, both, the rotations of the plastic hinges at the ends, which follow the above-described sectional moment-curvature diagram, and the elastic deformation of the column. The flexural capacity of the column is compared to its shear capacity and to the joint capacity to obtain the actual capacity of the column element.

The analytical expressions for the force capacity $v_{x L S}$ and the corresponding displacement $u_{x L S}$ at the three limit states $x=D, L, C$ are obtained from equilibrium and compatibility conditions as:

$$
\begin{aligned}
& v_{x L S}=\min \left\{\frac{2 M_{x L S}-N u_{x L S}}{H} \quad V_{R} \quad V_{j R}-\left(A_{j t}+\kappa A_{j b}\right) f_{y}\right\} \\
& u_{x L S}=Q\left[\frac{2 M_{x L S}}{K_{E} H}+\phi_{x L S} L_{p}\left(H-L_{p}\right)\right]
\end{aligned}
$$

where $M_{x L S}$ is the flexural capacity at $x L S$ in Table $1 ; N$ is the axial load; $H$ is the column height; $V_{R}$ is the column shear capacity; $V_{j R}$ is the joint shear capacity; $A_{j t}$ and $A_{j b}$ are top and bottom rebars area passing through the joint or anchored in it, respectively, with $\mathrm{k}=1$ for internal joints and $k=0$ for external joints; $f_{y}$ is the steel yield tensile strength; and 
$\phi_{x L S}$ is the curvature capacity at $x L S$ in Table 1 . In the above equations, the p-delta factor $Q$, the elastic stiffness $K_{E}$, and the plastic hinge length $L_{p}$ are given by:

$$
\begin{gathered}
Q=\left(1+\frac{N}{K_{E} H}\right)^{-1} \\
K_{E}=\frac{12 E_{c} I}{\left(H-2 L_{p}\right)^{3}} \\
L_{p}=0.1 H+0.17 \frac{b+d}{2}
\end{gathered}
$$

where $E_{c}$ is the concrete elastic modulus and $I$ is the gross section moment of inertia.

The column shear capacity $V_{R}$ is computed as:

$$
V_{R}=0.9 d b f_{c} \omega_{w} \sqrt{\frac{\alpha_{c} v}{\omega_{w}}-1}
$$

where the term under square root should be within the interval $[1,2.5]$ and $\omega_{w}$. is the transverse reinforcement mechanical ratio:

$$
\omega_{w}=\frac{A_{s w}}{b s} \frac{f_{y}}{f_{c}}
$$

with $A_{s w}$ the transverse reinforcement area, while $v=0.5$ is the concrete compressive strength reduction factor and $\alpha_{c}$ depends on the normalized axial load $n_{S}$, as follows:

$$
\alpha_{c}= \begin{cases}\min \left(1+n_{S}, 1.25\right) & 0.00 \leq n_{S}<0.50 \\ 2.5\left(1-n_{S}\right) & 0.50 \leq n_{S}<1.00\end{cases}
$$

The joint shear capacity $V_{j R}$ is computed as:

$$
V_{j R}=\eta d_{c} b_{j} f_{c} \sqrt{1-\frac{n_{S}}{\eta}}
$$

where $d_{c}=b_{y}$ in Figure $3, b_{j}$ is the joint effective width, and $\eta=\alpha_{j}\left(1-f_{c} / 250\right)$ with $f_{c}$ in $\mathrm{MPa}$, with $\alpha_{j}=0.6$ for internal joints and $\alpha_{j}=0.48$ for external joints.

\subsection{Story Capacity for the Three LSs}

A story is considered as a parallel system of $j=1 \ldots m$ columns elements. The $i$-th interstory drift capacity $d_{x L S, i}$ and the resultant force $V_{x L S, i}$ at $x=D, L, C$ are verified when the first column reaches the corresponding limit state:

$$
\begin{gathered}
d_{x L S, i}=\min _{j} u_{x L S, j} \\
V_{x L S, i}=\sum_{j=1}^{m} v_{j}\left(d_{x L S, i}\right)
\end{gathered}
$$

where $u_{x L S, j}$ is the $j$-th column displacement at $x L S$ and $v_{j}\left(d_{x L S, i}\right)$ is the $j$-th column force at $d_{x L S, i}$. The $i$-th interstory secant stiffness is:

$$
k_{x L S, i}=\frac{V_{x L S, i}}{d_{x L S, i}}
$$




\subsection{Frame Capacity for the Three LSs}

The frame is characterized as a series system (so-called "stick model") of $i=1 \ldots n$ stories, where individual story masses $m_{i}$ are located at height $z_{i}$ (Figure 4 ) and where the connecting elements follow the respective trilinear story behavior, achieved from the trilinear columns behavior, in turn determined from the trilinear sectional behavior, as explained in the previous sections. In such a system, the horizontal forces are applied along the frame height having a distribution of the shape $\psi_{i}$, which can be either heightproportional or mass-proportional:

$$
\psi_{i}=\frac{m_{i} z_{i}}{\sum m_{i} z_{i}} \quad \text { or } \quad \psi_{i}=\frac{m_{i}}{\sum m_{i}}
$$

where it should be observed that $\sum \psi_{i}=1$.

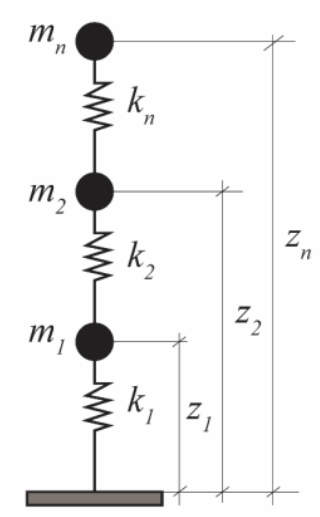

Figure 4. Frame as a stick-model series system.

From the applied force shape $\psi_{i}$, the interstorey shear shape $\tau_{i}$ is obtained as:

$$
\tau_{i}=\sum_{j=i}^{n} \psi_{j}
$$

The elastic interstorey displacement shape $\varphi_{i}$ can be found as:

$$
\varphi_{i}=\frac{\tau_{i}}{k_{D L S, i}}\left(\sum_{j=1}^{n} \frac{\tau_{j}}{k_{D L S, j}}\right)^{-1}
$$

with $k_{D L S, i}$ being the $i$-th story elastic stiffness at DLS.

The frame displacement capacity $d_{x L S}$ and resulting base-shear $V_{x L S}$ at $x=D, L, C$ are defined when the first story reaches the corresponding limit state:

$$
\begin{aligned}
d_{x L S} & =\min _{i} \frac{d_{x L S, i}}{\varphi_{i}} \\
V_{x L S} & =\min _{i} \frac{V_{x L S, i}}{\tau_{i}}
\end{aligned}
$$

where $d_{x L S, i}$ is the $i$-th interstorey drift in Equation (17) at $x L S$, normalized with respect to Equation (22), and $V_{x L S, i}$ is the $i$-th interstorey shear in Equation (18), normalized with respect to Equation (21). Note that the two normalized minima always identify the same story. 


\section{Determination of Displacement Demand on a 2D Frame}

\subsection{Simplified Modal Analysis}

The first modal shape $\phi$ can be assumed equal to the displacement shape. In "stick models", this is a reasonable approximation, because the error is negligible since it is lower than $3 \%$ for both the eigenvalue ratio and the eigenvector distance norm. Therefore:

$$
\phi_{i}=\sum_{j=1}^{i} \varphi_{j}
$$

where it should be noted that, by replacing Equation (22), the maximum value at the top $(i=n)$ is naturally equal to 1 .

The participation factor $\Gamma$ is:

$$
\Gamma=\frac{m^{*}}{m_{\bmod }}
$$

where $m^{*}=\sum m_{i} \phi_{i}$ is the effective mass and $m_{m o d}=\sum m_{i} \phi_{i}^{2}$ is the modal mass.

\subsection{Equivalent SDOF System}

The "stick model" of the frame is then transformed into an equivalent single degreeof-freedom (SDOF) system, whose top displacements $\left(d^{*}\right)$ and base-shears $\left(V^{*}\right)$ at the three LSs $x=D, L, C$ are determined from Equations (23) and (24), as follows:

$$
\begin{aligned}
& d_{x L S}^{*}=\frac{d_{x L S}}{\Gamma} \\
& V_{x L S}^{*}=\frac{V_{x L S}}{\Gamma}
\end{aligned}
$$

From which the effective elastic stiffness can be computed as:

$$
K_{D L S}^{*}=\frac{V_{D L S}^{*}}{d_{D L S}^{*}}=\frac{V_{D L S}}{d_{D L S}}
$$

\subsection{Bilinearization of the Interstorey Capacity Curve}

The SDOF system capacity curve is calculated by the equality of the two areas (assuming the same dissipated energy) between the bilinear equivalent curve and the trilinear curve previously defined for the DLS, LLS, and CLS. The yield point and the base-shear for the bilinear equivalent SDOF system is therefore found as:

$$
\begin{gathered}
d_{y}^{*}=\frac{V_{y}^{*}}{K_{D L S}^{*}} \\
V_{y}^{*}=V_{D L S}^{*}\left[\frac{d_{C L S}^{*}}{d_{D L S}^{*}}-\sqrt{\left(\frac{d_{C L S}^{*}}{d_{D L S}^{*}}\right)^{2}-\frac{d_{L L S}^{*}}{d_{D L S}^{*}}+\frac{V_{C L S}^{*}}{V_{D L S}^{*}}\left(\frac{d_{L L S}^{*}}{d_{D L S}^{*}}-\frac{d_{C L S}^{*}}{d_{D L S}^{*}}\right)+\frac{V_{L L S}^{*}}{V_{D L S}^{*}}\left(1-\frac{d_{C L S}^{*}}{d_{D L S}^{*}}\right)}\right]
\end{gathered}
$$

The elastic period of such a bilinearized system is:

$$
T^{*}=2 \pi \sqrt{\frac{m^{*}}{K_{D L S}^{*}}}=2 \pi \sqrt{m^{*} \frac{d_{D L S}}{V_{D L S}}}
$$

where $m^{*}=\sum m_{i} \phi_{i}$ and $K_{D L S}^{*}$ is in Equation (29). 


\subsection{Displacement Demands for the Three LSs}

The displacement demands on the frame system corresponding to $x=D, L, C$ are found from the elastic displacement spectral ordinates $S_{D e, x L S}\left(T^{*}\right)$ calculated at $T^{*}$ from Equation (32) on the displacement spectra pertaining to $x=D, L, C$, as:

$$
d_{x L S, D}=\Gamma \cdot S_{D e, x L S}\left(T^{*}\right) \cdot \begin{cases}1 & \text { if } T^{*} \geq T_{C, x L S} \\ \frac{1}{q^{*}}\left[1+\left(q^{*}-1\right) \frac{\left.T_{C, x L S}\right]}{T^{*}}\right] & \text { if } T^{*}<T_{C, x L S}\end{cases}
$$

where $T_{C, x L S}$ is the period at the onset of the descending branch of the acceleration spectrum and:

$$
q^{*}=\frac{m^{*} \cdot S_{e, x L S}\left(T^{*}\right)}{V_{y}^{*}} \geq 1
$$

where $m^{*}=\sum m_{i} \phi_{i}, V_{y}^{*}$ is in Equation (31), and $S_{e, x L S}\left(T^{*}\right)$ are the spectral ordinates calculated at $T^{*}$ on the elastic acceleration spectra pertaining to $x=D, L, C$. It is important to note that the spectral shape varies based on the soil class.

\section{Validation of the Proposed Simplified Mechanical Model}

The proposed simplified pushover analysis method is validated through its application on three different $R C$ frames shown in Figure 5 and subsequently comparing the results with rigorous nonlinear static analysis.

\begin{tabular}{|llll|}
\hline Section & Dimension & Reinforcement & Stirrup \\
$C 1$ & $25 \times 25 \mathrm{~cm}$ & $4 \varnothing 16$ & $\varnothing 8 / 150 \mathrm{~mm}$ \\
$C 2$ & $30 \times 30 \mathrm{~cm}$ & $4 \varnothing 16$ & $\varnothing 8 / 150 \mathrm{~mm}$ \\
$C 3$ & $35 \times 35 \mathrm{~cm}$ & $4 \varnothing 16$ & $\varnothing 8 / 150 \mathrm{~mm}$ \\
Beam & $30 \times 50 \mathrm{~cm}$ & $4 \varnothing 16(T)$ & $\varnothing 8 / 100 \mathrm{~mm}$ \\
& & $4 \varnothing 16(B)$ & \\
\hline
\end{tabular}

- The column sections layout is symmetric for case 2 and case 3

- Storey height is 3 meters for all cases

\begin{tabular}{|c|c|c|c|c|c|c|c|c|c|c|}
\hline \multirow{3}{*}{\multicolumn{3}{|c|}{ Case 1 (3 story) }} & \multicolumn{4}{|c|}{ Case 2 (5 story) } & $C l$ & $\mathrm{Cl}$ & $\mathrm{Cl}$ & \\
\hline & & & $C 1$ & $C 1$ & $\mathrm{Cl}$ & & $C l$ & $C 1$ & $C 1$ & \\
\hline & & & $C 1$ & $C 1$ & $C 1$ & & $C 1$ & $C 1$ & $C 1$ & \\
\hline $\mathrm{Cl}$ & $\overline{C l}$ & $\mathrm{Cl}$ & $C 1$ & Cl & $C l$ & & $\overline{C l}$ & $C l$ & $C l$ & \\
\hline$C 1$ & $\mathrm{Cl}$ & $C l$ & $C 2$ & $C 2$ & $C 2$ & & $C 1$ & $C 2$ & $C 2$ & \\
\hline $\mathrm{Cl}$ & $C 1$ & $C 1$ & $C 2$ & $C 3$ & C3 & & $\overline{C l}$ & $C 3$ & $C 3$ & \\
\hline $2,5 n$ & $5 m$ & $5 m$ & $5 n$ & $5 m$ & $5 m$ & $5 r$ & & $5 m$ & $5 m$ & $5 m$ \\
\hline
\end{tabular}

Case 3 (6 story)

Figure 5. Geometry and sectional details of the case study frames.

\section{Application of the Proposed Model}

Three reinforced concrete frames with a varying number of stories are considered for the comparative application of the proposed method. The frames considered are designed for gravity loads only, according to common practice in Italy in the pre-1980s, before the introduction and enforcement of seismic codes and capacity design. A common failure mechanism found in such gravity-load-designed structures is column-swaying, due to the presence of strong beams and weak columns, which results in a shear-type overall behavior.

Figure 5 shows various details of the $\mathrm{RC}$ frames such as: frames geometry, element cross sections, longitudinal, and shear reinforcement. The concrete and reinforcing steel strength were 18 and $370 \mathrm{MPa}$, respectively, which were typically used in Italy in the 1970s. Static nonlinear pushover analysis was conducted using SAP2000 software [31] and the displacements at the attainment of three limit states DLS, LLS, and CLS were retrieved for 
each case, consistent with the criteria adopted for the simplified method. Figure 6 shows the comparison of the displacement quantities at DLS, LLS, and CLS obtained through the accurate pushover analyses and the proposed simplified analytical model. It is evident from the displacement comparison at various limit states that the proposed model provides a satisfactory match with the full pushover analysis. The error in terms of drift at various limit states between the two methods for the three case studies is shown in Table 2, where $(+)$ and $(-)$ signs stand for overestimation and underestimation, respectively. Based on the results, the error is deemed to be acceptable. Moreover, it is observed that in case 1 the damage concentration occurs at the first story, while for cases 2 and 3 the damage is concentrated at the third story. It should also be noted that the stiffness is generally higher using the simplified method, except for LLS and CLS of case 3. The mechanical model performs well to capture the deformed shape at the elastic limit (DLS) and subsequently at the inelastic range (LLS and CLS) and the formation of soft stories. Furthermore, in Figure 7, the pushover curves of the RC frames in terms of base shear-top displacement obtained from the two methods are compared, showing a satisfactory correspondence.

$-\rightarrow-$ Pushover $\rightarrow$ Proposed method
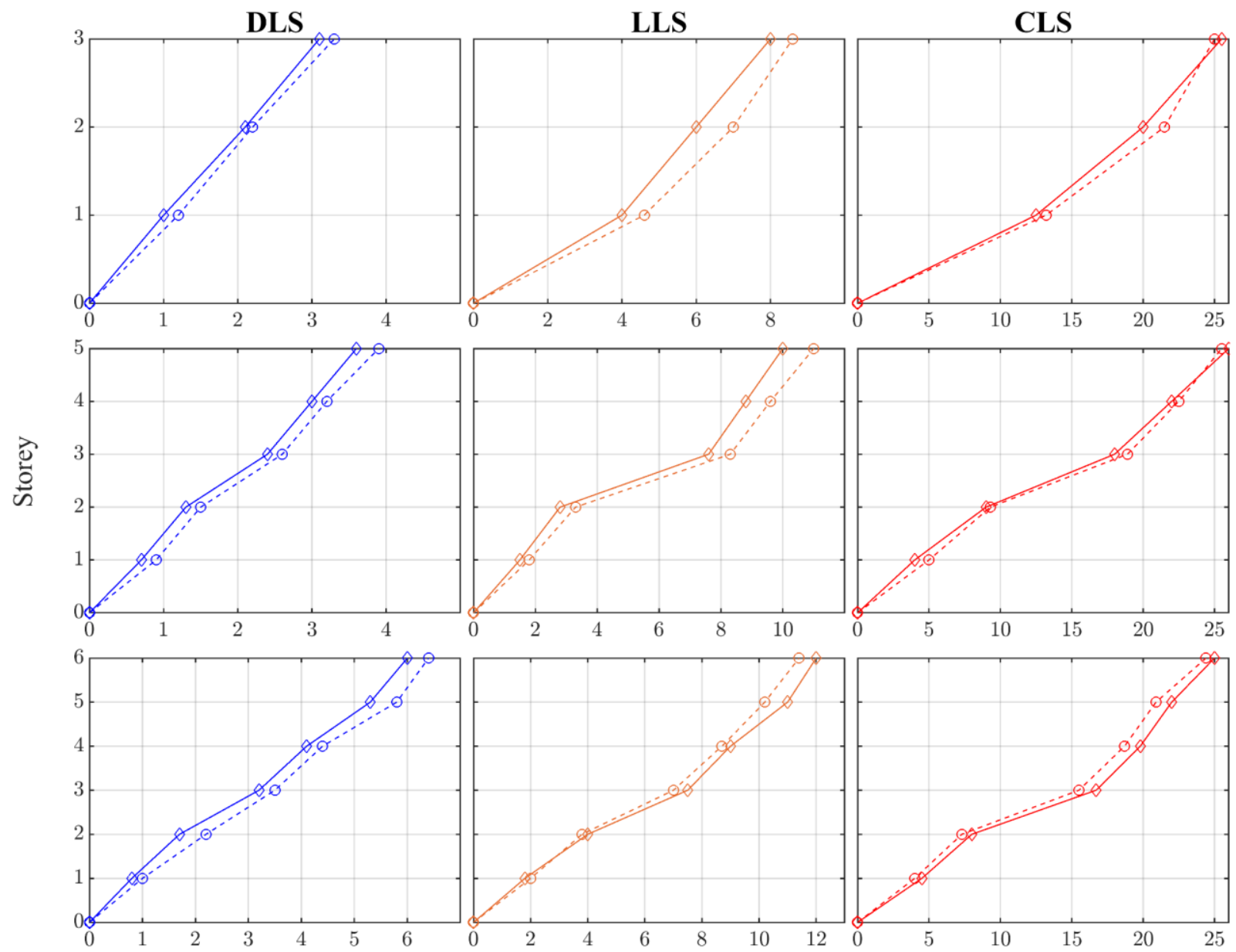

Displacement $(\mathrm{cm})$

Figure 6. Comparison of the displacement profiles from the full pushover analysis (dashed lines) and the proposed analytical method (thick lines). From above: Case 1 (3 storeys), Case 2 (5 storeys), and Case 3 (6 storeys). 
Table 2. Drift error between rigorous pushover and proposed method.

\begin{tabular}{|c|c|c|c|c|c|c|c|c|c|}
\hline \multirow{2}{*}{ Story } & \multicolumn{3}{|c|}{ Case 1 (Error \%) } & \multicolumn{3}{|c|}{ Case 2 (Error \%) } & \multicolumn{3}{|c|}{ Case 3 (Error \%) } \\
\hline & DLS & LLS & CLS & DLS & LLS & CLS & DLS & LLS & CLS \\
\hline 1 & -16.7 & -13.0 & -5.3 & -22.2 & -16.7 & -20.0 & -20.0 & -10.0 & +12.5 \\
\hline 2 & -4.5 & -14.3 & -7.0 & -13.3 & -15.2 & -3.2 & -22.7 & +5.3 & +9.6 \\
\hline 3 & -6.1 & -7.0 & 2.0 & -7.7 & -8.4 & -4.8 & -8.6 & +7.1 & +7.7 \\
\hline 4 & & & & -6.3 & -8.3 & -2.2 & -6.8 & +3.4 & +5.9 \\
\hline 5 & & & & -7.7 & -9.1 & 2.0 & -8.6 & +7.8 & +5.3 \\
\hline 6 & & & & & & & -6.3 & +5.3 & +2.5 \\
\hline Average & -9.1 & -11.4 & -3.4 & -11.4 & -11.5 & -5.6 & -10.4 & +2.7 & +6.2 \\
\hline
\end{tabular}

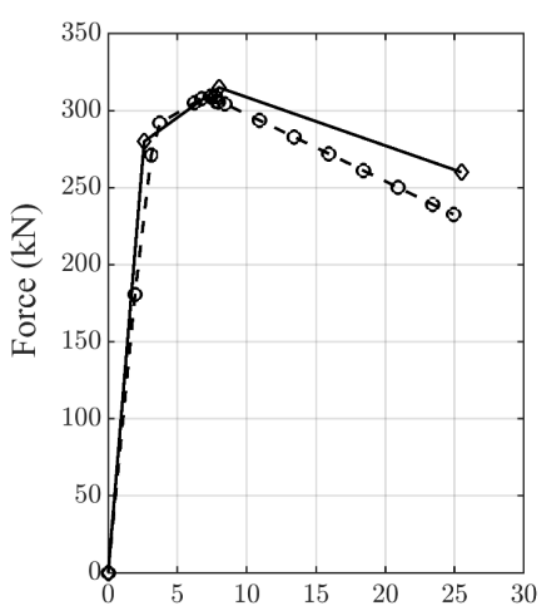

(a)

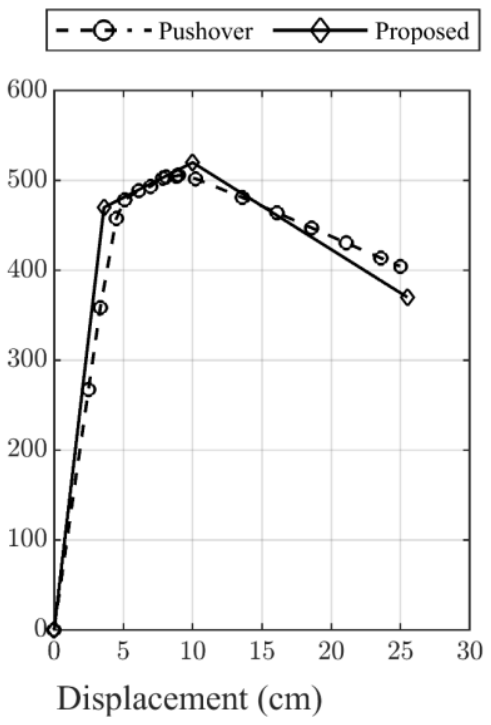

(b)

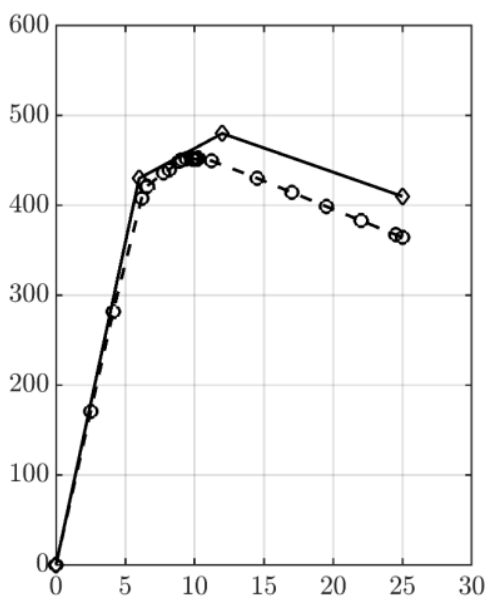

(c)

Figure 7. Comparison of the capacity curves from the full pushover analysis (dashed lines) and the proposed analytical method (thick lines): (a) Case 1 (3 storeys); (b) Case 2 (5 storeys); (c) Case 3 (6 storeys).

\section{Vulnerability Analysis through the Proposed Simplified Method}

The proposed analytical pushover analysis on the simplified (stick-)model of a building becomes very useful when studying the impacts of earthquakes and developing risk assessment maps, in order to prioritize regions for structural retrofitting policies. In this study, the aim is to divide the building stock considered into different typologies, based on some macro-features (structure type, number of stories, age of construction, etc.) and then correctly describe the vulnerability of each typology. This is performed through the socalled fragility curves, which may be based on either an observational approach accounting for the damages observed in previous earthquakes, or a mechanical approach based on numerical models. As for the latter approach, in the literature, the fragility curves may be obtained from either incremental dynamic analysis (IDA) or nonlinear static analysis. Despite the accuracy of IDA, researchers are often discouraged to use it, since the computational effort it requires renders the analysis of large-building inventories an onerous task. In this respect, static analyses may be preferred, especially if they make use of simplified mechanical models. Having a small number of basic variables, the computational effort becomes affordable. In that respect, the fully analytical approach proposed in this study is even more effective, since fragility curves can be obtained very straightforwardly by parametrizing the basic variables of interest and by running a large number of analyses on different models in a very short time. It is a very efficient method, especially when dealing with a large inventory of buildings at a territorial scale. 


\section{Application of the Proposed Model in Vulnerability Assessment}

The potential of the proposed simplified mechanical model is demonstrated by developing, through Monte Carlo analysis, the fragility curves of a five-story building typology, whose geometry is shown in Figure 5. The proposed model allows conducting multiple capacity assessment checks with minimal computational effort, by randomly extracting the input data in each realization of a building sample. The variable data considered were concrete strength, steel strength, and flexural and shear reinforcement amounts. They were extracted from uniform distributions considering the ranges shown in Table 3. This results in a data cloud that can be statistically treated to construct fragility curves at predefined limit states.

Table 3. Ranges adopted for material strengths, and for shear and flexural reinforcement.

\begin{tabular}{cccccc}
\hline & $\begin{array}{c}\text { Concrete } \\
\text { Strength } f_{y m} \\
\mathbf{( M P a )}\end{array}$ & $\begin{array}{c}\text { Steel } \\
\text { Strength } f_{y m} \\
\mathbf{( M P a )}\end{array}$ & $\begin{array}{c}\text { Flexural } \\
\text { Reinforcement } \rho_{s} \\
\mathbf{( \% )}\end{array}$ & $\begin{array}{c}\text { Stirrup } \\
\text { Diameter } \phi_{s t} \\
(\mathbf{m m})\end{array}$ & $\begin{array}{c}\text { Stirrup } \\
\text { Spacing } S_{s t} \\
(\mathbf{m m})\end{array}$ \\
\hline $\begin{array}{c}\text { Uniform } \\
\text { distribution type }\end{array}$ & Continuous & Continuous & Continuous & Discrete & $150-250$ \\
\hline
\end{tabular}

The cumulative probability of exceedance of a limit state $(x L S$, with $x=D, L, C)$ is expressed as function of the horizontal peak ground acceleration, $a_{g}$. For each LS considered, for a given intensity measure $a_{g, k}, N_{i t}$ Monte Carlo analyses are performed and a set of displacement-based capacity/demand ratios $\rho=d_{x L S} / d_{i}\left(a_{g, k}\right)$ is obtained and subsequently statistically elaborated as:

$$
P_{x S L}\left(a_{g, k}\right)=P\left[D\left(a_{g, k}\right) \geq d_{x L S} \mid P G A=a_{g, k}\right]=\frac{1}{N_{i t}} \sum_{i=1}^{N_{i t}} \frac{d_{x L S}}{d_{i}\left(a_{g, k}\right)}
$$

where $P_{x L S}$ is the exceedance probability of the $x L S$ (with $x=D, L, C$ ) for the $k^{\text {th }}$ seismic intensity $a_{g, k}$, with $N_{i t}=1000$ and $k=1, \ldots, 52$, corresponding to $a_{g}=0.01 g, \ldots, 1.02 g$.

Once the probability for each $a_{g, k}$ is obtained, LSE nonlinear regression [32-34] is carried out to determine the parameters $\mu$ and $V$ of the lognormal cumulative distribution function expressed in terms of $a_{g}$ :

$$
P_{x S L}\left(a_{g}\right)=\Phi\left(\frac{1}{V} \ln \frac{a_{g}}{\mu}\right)
$$

where $\Phi(\cdot)$ is the standard normal cumulative distribution function, $\mu$ is the median of the capacity, and $V$ is the coefficient of variation, assumed as equal to the log-standard deviation, which is generally accepted up to 0.6 .

The numerical simulations were carried out using the @Risk software [35] on a simple spreadsheet. Figure 8 shows multiple capacity curves for the five-story building typology developed by randomly sampling the input data in Table 3 and performing 1000 iterations for each simulation. Table 4 shows the log-normal fragility curve parameters (mean $\mu$ and coefficient of variation $V$ ) of the PGA-based capacity for three limit states (DLS, LLS, and CLS) of the five-story frame, with the resulting fragility curves at various limit states shown in Figure 9. It should be noted that these fragility curves do not include the recordto-record (R2R) variability, so their dispersion is only that pertaining to the capacity. This is a feature of this analytical approach: to show how to account for the uncertainties in the capacity by running simplified pushover analyses, as opposed to complex numerical pushover analyses, whose computational effort may be significant within a Monte Carlo approach. As for the additional uncertainty due to demand, according to FEMA 695 [36], the R2R variability can be accounted for by SRSS-adding a forfeit log-standard deviation of 
0.2 and 0.4 for Serviceability and Ultimate Limit States, respectively. It should be noted that such forfeit values are still the object of further calibrations, which are beyond the scope of this study. In principle, one can obtain the fragility curves with the proposed method and subsequently add the demand variability either through the above (possibly recalibrated) forfeit values or through site-specific analyses. After including such demand dispersion, the shape of the curves will change, and the associated exceedance probability will increase.

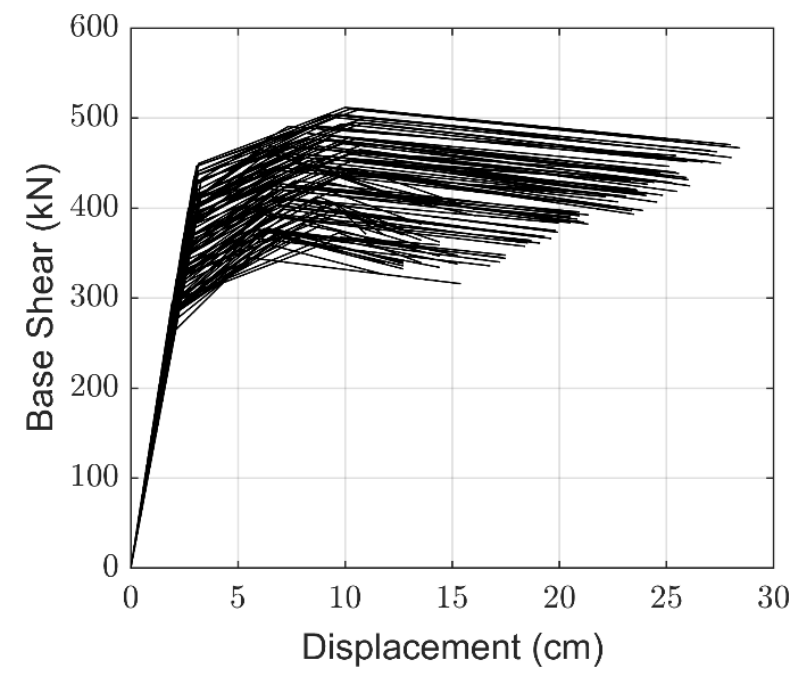

Figure 8. Parametric analytical pushover curves of the considered building typology for varying basic geometrical and mechanical parameters, given in Table 3.

Table 4. Fragility curve parameters (mean $\mu$ and coefficient of variation $V$ of the PGA-based capacity) for three Damage/Limit States.

\begin{tabular}{ccccccc}
\hline & DLS & \multicolumn{2}{c}{ LLS } & \multicolumn{2}{c}{ CLS } \\
\hline$\mu$ & $V$ & $\mu$ & $V$ & $\mu$ & $V$ \\
\hline 0.128 & 0.170 & 0.470 & 0.205 & 1.050 & 0.302 \\
\hline
\end{tabular}
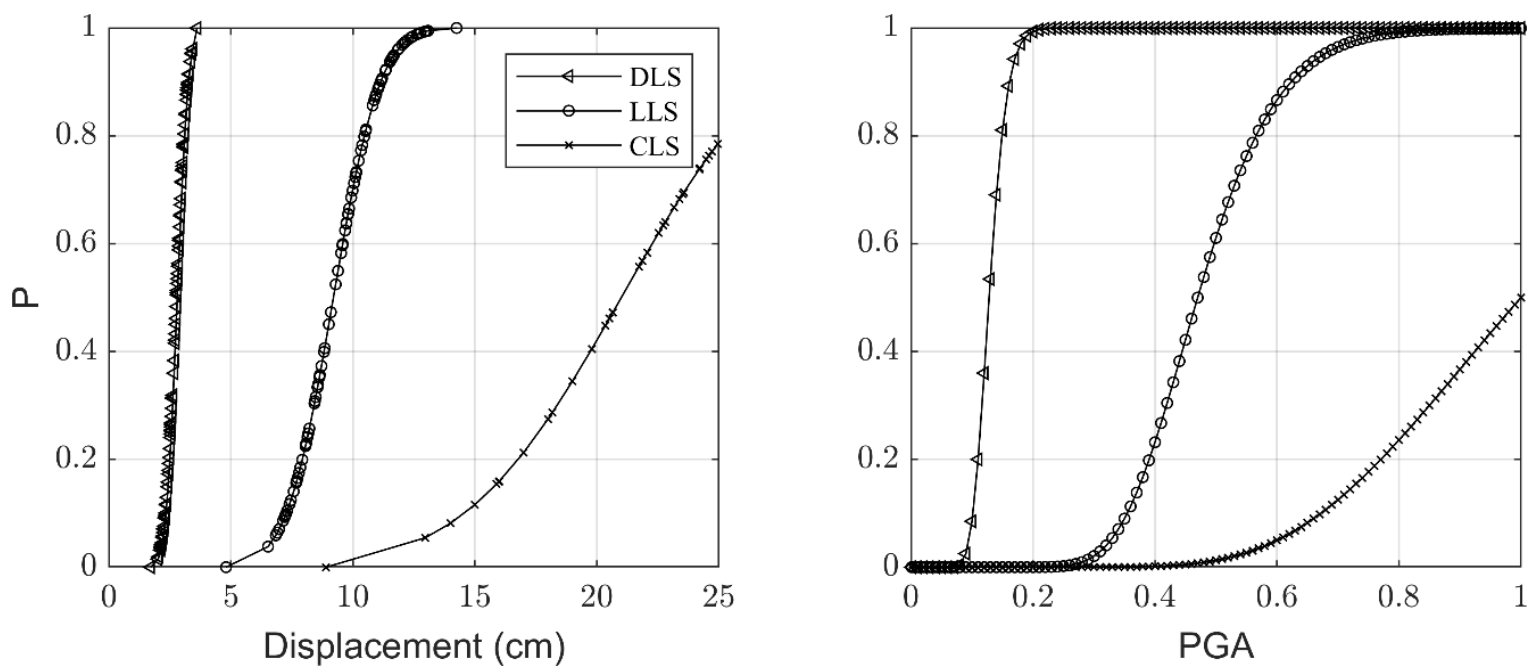

Figure 9. Fragility curves at the three considered limit states for the five-story building typology: LS-exceedance probability in terms of top displacement (left) and in terms of PGA, expressed in terms of $g$ (right). The fragility curves only contain the capacity dispersion, while the demand dispersion can be further added after calibration or site-specific studies relevant to record-to-record variability. 


\section{Conclusions}

An analytical method has been proposed to perform pushover analyses on reinforced concrete frames in a simplified yet accurate manner. The method is extremely efficient thanks to mechanics-based closed-form equations describing the capacity of the resisting mechanism, from the local to the global level, and can be readily implemented in a spreadsheet. Concise equations are provided, which are useful in performing rapid section and element capacity assessment. Overall, the procedure is conceived to be applied to existing buildings, under the assumption that their LS-exceedance is column-driven, as observed after significant earthquakes in most buildings designed with obsolete codes.

One merit of the simplified model is that it allows identifying the global capacity, expressed in terms of top-story displacement, by directly deriving it from the local capacities at the section and element level, for the three limit states (LS) of interest: Damage, Life Safety, and Collapse. The advantage is that there is no need to resort to different metrics, such as the largely $(\mathrm{ab})$ used interstorey drift, to define the attainment of a LS.

The accuracy of the proposed analytical model has been validated by applying it to three RC frames with different global geometry. The results have been compared with the results obtained from full pushover analyses using 2D FEM models. The results showed satisfactory accuracy in relation to the determination of the displacement profiles at various LSs, the identification of the weak stories, and especially the pushover curves, which showed a good match in terms of both total base-shear and top displacement. As an additional example, to show the potential of the method, the fragility curves pertaining to a five-story RC building typology have been built. This has been achieved by defining a set of varying mechanical and reinforcement parameters and by performing a Monte Carlo analysis with very limited computational effort.

The examples shown underline the computational effectiveness of the method, which lends itself to be adopted in large-scale risk/vulnerability assessment studies.

Author Contributions: Conceptualization, R.R.R., M.V. and G.M.; methodology, R.R.R., M.V. and G.M.; software, R.R.R.; validation, R.R.R. and G.M.; writing-original draft preparation, R.R.R.; writing-review and editing, R.R.R., M.V. and G.M.; supervision, G.M. and M.V. All authors have read and agreed to the published version of the manuscript.

Funding: This research was funded within the project DPC-ReLUIS 2019-21.

Institutional Review Board Statement: Not applicable.

Informed Consent Statement: Not applicable.

Data Availability Statement: Data is contained within the article.

Acknowledgments: No external acknowledgments are needed in this study.

Conflicts of Interest: The authors declare no conflict of interest.

\section{References}

1. Chopra, A. Dynamics of Structures: Theory and Applications to Earthquake Engineering; Prentice Hall: Hoboken, NJ, USA, 1995.

2. Fajfar, P.; Gašperšič, P. The N2 Method for the Seismic Damage Analysis of RC Buildings. Earthq. Eng. Struct. Dyn. 1996, 25, 31-46. [CrossRef]

3. Fajfar, P. A Nonlinear Analysis Method for Performance-Based Seismic Design. Earthq. Spectra 2000, 16, 573-592. [CrossRef]

4. NTC. Norme Tecniche Per Le Costruzioni; NTC: Rome, Italy, 2018.

5. Saiidi, M.; Sozen, M.A. Simple Nonlinear Seismic Analysis of R/C Structures. ASCE J. Struct. Div. 1981, 107, 937-952. [CrossRef]

6. Lawson, R.S.; Vance, V.; Krawinkler, H. Nonlinear Static Push-Over Analysis-Why, When, and How? In Proceedings of the Fifth US National Conference on Earthquake Engineering, Chicago, IL, USA, 10-14 July 1994; pp. 283-292.

7. Maison, B.F.; Bonowitz, D. How Safe Are Pre-Northridge WSMFs? A Case Study of the SAC Los Angeles Nine-Story Building. Earthq. Spectra 1999, 15, 765-789. [CrossRef]

8. Gupta, A.; Krawinkler, H. Seismic Demands for Performance Evaluation of Steel Moment Resisting Frame Structures; Stanford University: Stanford, CA, USA, 1999.

9. Gupta, A.; Krawinkler, H. Estimation of Seismic Drift Demands for Frame Structures. Earthq. Eng. Struct. Dyn. 2000, 29, 1287-1305. [CrossRef] 
10. Skokan, M.J.; Hart, G.C. Reliability of Nonlinear Static Methods for the Seismic Prediction of Steel Frame Buildings. In Proceedings of the Structures Congress 2000: Advanced Technology in Structural Engineering, Philadelphia, PA, USA, 8-10 May 2004; Volume 103, pp. 1-8.

11. Krawinkler, H.; Seneviratna, G.D.P.K. Pros and Cons of a Pushover Analysis of Seismic Performance Evaluation. Eng. Struct. 1998, 20, 452-464. [CrossRef]

12. Miranda, E.; Bertero, V. Evaluation of Strength Reduction Factors for Earthquake-Resistant Design. Earthq. Spectra 2019, 10, 357-379. [CrossRef]

13. Gupta, B.; Kunnath, S.K. Adaptive Spectra-Based Pushover Procedure for Seismic Evaluation of Structures. Earthq. Spectra 2000, 16, 367-391. [CrossRef]

14. Paret, T.; Sasaki, K.; Eilbeck, D.; Freeman, S. Approximate Inelastic Procedures to Identify Failure Mechanisms from Higher Mode Effects. In Proceedings of the 11th World Conference on Earthquake Engineering, Emeryville, CA, USA, 23-28 June 1996.

15. Sasaki, K.; Freeman, S.; Paret, T. Multimode Pushover Procedure (MMP)—A Method to Identify the Effects of Higher Modes in a Pushover Analysis. In Proceedings of the 6th US National Conference on Earthquake Engineering, Washington, DC, USA, 31 May-4 June 1998.

16. Matsumori, T.; Otani, S.; Shiohara, H. Earthquake Member Deformation Demands in Reinforced Concrete Frame Structures. In Proceedings of the US-Japan Workshop on Performance-Based Earthquake Engineering Methodology for R/C Building Structures, Tokyo, Japan, 10-11 September 1999; pp. 79-94.

17. Freeman, S. Evaluations of Existing Buildings for Seismic Risk-A Case Study of Puget Sound Naval Shipyard. In Proceedings of the 1st US National Conference on Earthquake Engineering, Washington, DC, USA, 18-20 June 1975; pp. 113-122.

18. Shibata, A.; Sozen, M.A. Substitute-structure method for seismic design in R/C. ASCE J. Struct. Div. 1976, 102, 1-18. [CrossRef]

19. Fajfar, P.; Fischinger, M. N2-A Method for Non-Linear Seismic Analysis of Regular Buildings. In Proceedings of the Ninth World Conference in Earthquake Engineering, Tokyo, Japan, 2-9 August 1988; pp. 111-116.

20. Kappos, A.; Paraskeva, T.; Sextos, A. Seismic Assessment of a Major Bridge Using Modal Pushover Analysis and Dynamic Time-History Analysis. In Proceedings of the International Conference on Computational and Experimental Engineering and Sciences, Oxford, UK, 6-8 April 2004.

21. Aydenoglu, M. An Improved Pushover Procedure for Engineering Practice: Incremental Response Spectrum Analysis (IRSA). In Proceedings of the Workshop Performance-Based Seismic Design. Concepts and Implementation, Bled, Slovenia, 28 June-1 July 2004.

22. Kappos, A.; Paraskeva, T.; Sextos, A. Modal Pushover Analysis as a Means for the Seismic Assessment of Bridge Structures. In Proceedings of the 4th European Workshop on the Seismic Behaviour of Irregular and Complex Structures, Thessaloniki, Greece, 26-27 August 2005; pp. 26-27.

23. FEMA. 356 Prestandard and Commentary for the Seismic Rehabilitation of Buildings; FEMA: Washington, DC, USA, 2000.

24. Hall, J.F. On the Descending Branch of the Pushover Curve for Multistory Buildings. Earthq. Eng. Struct. Dyn. 2018, 47, 772-783. [CrossRef]

25. New Zealand Standards. Structural Design Actions Part 5: Earthquake Actions; New Zealand Standards: Wellington, New Zealand, 2004.

26. ATC-40. Seismic Evaluation and Retrofit of Concrete Buildings; Applied Technology Council: Redwood City, CA, USA, 1996 ; Volume 1.

27. Vailati, M.; Monti, G.; Khazna, M.; Napoli, A.; Realfonzo, R. Probabilistic Assessment of Masonry Building Clusters. In Proceedings of the 15th WCEE-World Conference of Earthquake Engineering, Lisboa, Portugal, 15 September 2015.

28. Vailati, M.; Monti, G.; Khazna, M.J.; Realfonzo, R.; De Iuliis, M. Probabilistic Seismic Response Analysis of Existing Masonry Structures. Brick Block Mason. 2016, 2489-2498. [CrossRef]

29. Vailati, M.; Monti, G.; di Gangi, G. Assessment of Masonry Building Clusters with a Dedicated NLA Software. Appl. Mech. Mater. 2016, 847, 191-203. [CrossRef]

30. Monti, G.; Petrone, F. Yield and Ultimate Moment and Curvature Closed-Form Equations for Reinforced Concrete Sections. ACI Struct. J. 2015, 112, 463-474. [CrossRef]

31. Computers and Structures Inc. Integrated Software for Structural Analysis and Design; Computers and Structures Inc.: Berkeley, CA, USA, 2000.

32. Rossetto, T.; Ioannou, I.; Grant, D. Existing Empirical Fragility and Vulnerability Functions: Compendium and Guide for Selection; GEM Foundation: Pavia, Italy, 2013.

33. Rossetto, T.; Ioannou, I.; Grant, D.; Maqsood, T. Guidelines for Empirical Vulnerability Assessment; GEM Foundation: Pavia, Italy, 2014.

34. Ioannou, I.; Rossetto, T.; Grant, D. Use of Regression Analysis for the Construction of Empirical Fragility Curves. In Proceedings of the 15th World Conference on Earthquake Engineering, Lisboa, Portugal, 24-28 September 2012.

35. Palisade @Risk Palisade Decision Making Tool. 2020. Available online: https:/ / www.palisade.com/ (accessed on 6 December 2021).

36. FEMA. P.695-Quantification of Building Seismic Performance Factors; FEMA: Washington, DC, USA, 2009. 